\title{
EVALUATION OF THE SUPERPLASTICIZER EFFECT ON THE CONCRETE COMPRESSIVE STRENGTH USING THE TREE-CLASSIFICATION DECISION ALGORITHM
}

\author{
Hadi Davoudi \\ Department of Civil Engineering, Islamic Azad University, Kazeroon City, Iran
}

\begin{abstract}
Concrete is the most important material in the civil engineering. The concrete compressive strength is a non-linear function of the concrete age and some constituents. These constituents include cement, blast furnace slag, fly ash, superplasticizer, coarse aggregate and fine aggregate. The superplasticizers are among elements which are important in increasing the concrete compressive strength and we are going to analyze here using the tree-classification decision algorithm. The decision trees, usually, are used in classification of a bunch of data. J48 is one of the most favoured ones. The decision trees are developed using information entropy on a collection of training data. J48 is a recursive algorithm that combines the remaining of the following data sets and continues normalizing the output data using the separation process until a uniform classification result obtains. This article evaluates the superplasticizer effect on the concrete compressive strength using the tree-classification decision algorithm.
\end{abstract}

\section{KEYWORDS}

Concrete compressive strength, superplasticizer, tree-classification decision algorithm

\section{INTRODUCTION}

Concrete compressive strength is a non-linear function of the concrete age and its constituents. These constituents include cement, blast furnace, fly ash, superplasticizer, coarse aggregate and fine aggregate. The concrete is the only constituents which can be delivered to the working site in the plasticity form. This feature turns it into a notable construction material because it can be cast in any form.

The cement strength is determined by the proportion of the concrete, coarse and fine aggregate, water and other different mixtures. The water-cement ratio is the main factor in the concrete strength. The superplasticizers have very important role in the concrete compressive strength. Their function in the concrete started from the 1960s and it considered as a benchmark in the concrete technology and construction field. With the application of the superplasticizers the concrete obtained high functionality and low w/c ratio. We want to analyze the relation of the concrete compressive strength and the superplasticizers using the tree-classification decision algorithm (J48 Algorithm). The structure of the article is as follows: The second chapter is the study of the previous literature and the related definitions. The third chapter covers the superplasticizers. And the fourth chapter describes the tree-classification decision algorithm, the fifth chapter approaches the data analysis and the sixth chapter includes the conclusion. 


\section{THE RELATED LITERATURE}

Tattersall and etc. all; described the advantages and disadvantages of the applied tests in determining the concrete strength and efficiency. He pointed to the main problems in these tests and also determined how much increasing the percentage of the superplasticizer, which retains the w/c ratio, increases the slump, and also determined its effect on the concrete strength.

There is also a precious study done by the Erdogdu. He tried to find a solution for recovering the initial slump of the concrete on the working place. He used water and superplasticizer to remix the concrete (re-temper) and compared the results. The concrete recombined with the superplasticizer, notwithstanding the mixing time $[6,7,8]$.

One of the important levels in the concrete mixing plan is using the superplasticizer. This material increase the concrete's compressive strength and efficiency decrease the w/c ratio and yet retain the strength and efficiency and decreases the permeability [10].

Pereira \& colleagues studied the effect of the superplasticizers on the concrete compressive strength and efficiency using the retrieved concrete fine grains [11]. They also studied the effect of the superplasticizers on the splitting tensile strength [12].

According to the statements of the Yamakava, superplasticizers have positive effects on concrete properties in its fresh and hardened form. In the fresh form, using the superplasticizers decreases the bleeding inclination of the concrete due to the decrease in the w/c ratio but if the w/c ratio retains, then the superplasticizers increases the concrete setting time because there is more water to plasticize the mixture [13].

\subsection{Concrete compressive strength}

Concrete is the most important material in the civil engineering. The concrete compressive strength is a non-linear function of the concrete age and other elements. These elements include cement, blast furnace slag, fly ash, superplasticizer, coarse aggregate and fine aggregate. The concrete is the only constituents which can be delivered to the working place in the plasticity form. This feature turns it into a notable construction material because it can be moulded in any form. It creates a great variety in the surface textures and colours and can be used in the construction of the highways, streets, bridges, dams, big buildings, airport runways, jetties, bulwarks, silo and farm buildings, houses, and even boats and ships.

Two main constituents of the concrete are cement paste and neutral materials. The cement paste consists of the Portland cement, water and some air in the form of the trapped bubbles. And the neutral materials include the fine aggregate like sand and coarse aggregate like grovel, broken stone or slag.

The concrete compressive strength is sorted in the batching plant for each classification, to keep the concrete's high quality during the casting. The cast concretes' samples are tested under the compressive loads to determine the concrete compressive strength. The compressive strength is calculated by applying the failure load on the surface usually after 28 days of curing. It is controlled by the ratio of the cement, coarse and fine aggregates, water and other various constituents.

The w/c ratio is the main factor in concrete compressive strength. The lower the w/c ratio, the higher is the compressive strength. Cement hardening depends on the correct chemical reaction of its constituents and accordingly it needs the minimum of water possible. The excess water may increase the fluidity but decreases the strength. 
The compressive strength of each material is defined as its resistance to failure posed by the compressive loads. Especially for the concrete, the compressive strength is an important parameter to determine the function of a material during the service. In order to achieve the intended engineering features and the required strength, the concrete mixture can be proportioned. Some of the other features of the hardened concrete are elasticity module, tensile strength, creep rate, density, and thermal expansion index and so on.

\subsection{Cement}

Cement is material with adhesion properties which provides the possibility of the adhesion of the mineral constituents in a solid mass. Cement consists of the lime silicates and aluminates originate from limestone and clay (or shell) which has been mixed and fused in the furnace and turned into a powder. Cement combines with the water chemically and (hydration) and create the hardened mass. The hydraulic standard cement is known as Portland cement because of its similarity to Portland stone quarried on the isle of Portland in Dorset, England. This name is derived from the name first used in a patent owned by Joseph Aspdin from Leeds, England 1824.

\subsection{Water and its effect}

Water has two roles in concrete mixture. First, it reacts with cement chemically and hydrolyzes it; second, it makes the concrete fluid and functional. The water used for make concrete is drinkable water. The impurity of the water can have an adverse effect on the concrete strength.

\section{SUPER PLASTICIZER}

Kenichi Hattori from japan introduced the first superplasticizer in 1964 which consisted of betanaphthalene sulfonate. The second was Melment introduced in Germany in the same year and consisted of melamine formaldehyde sulfonate condensation. It was after a decade that the application of the superplasticizers was introduced to America Continent $[1,4,5]$.

The application of the superplasticizers in the concrete started from the 1960s and got known in the concrete technology and the construction field as a benchmark. This way concrete was created with a higher functionality and strength. With adding superplasticizers, the concrete got higher efficiency and yet lower w/c. The superplasticizers are the polyelectrolytes with organic origin which act like the distribution of the chemicals in the heterogeneous system [2].

These materials are high reactive. They do not have sulfonic group and get ionized completely in an alkali environment. The super-plasticizers with high reactivity that do not defer the concrete's curing in high doses. Make it possible to produce cement with high amount of fly ash or slag.

The superplasticizers are the macromolecules which are hundreds of times larger than the water molecule. Because of the function of the CA3, the mechanism of the superplasticizers is defined as the surface absorption. The superplasticizers repel the similar charges and producing water gets trapped and hence decreases the density. The mechanism of the superplasticizers is somewhat different from the WRA. The difference depends on the consistency of the superplasticizers with Portland cement. It is necessary to know that the superplasticizers in the cement particles won't be fixed by the $\mathrm{C} 3 \mathrm{~A}$ because this decreases the cement efficiency.

The common dose of the superplasticizer used to increase the cement efficiency varies between 13 litters per cubic meter and the liquid super-plasticizer includes $40 \%$ active elements. In the process of the w/c ratio reduction, a higher dose of relatively 5-20 litters per cubic meter of the concrete is used. 
The required dose for the cement mixture is unique and is determined by the Marsh Cone test. The superplasticizers are commonly classified in the following polymer groups:

- $\quad$ Melamine formaldehyde sulfonate condensation (SMF)

- $\quad$ Beta-naphthalene sulfonate (SNF)

- $\quad$ Lingo-sulfonate (MLS)

- Derivatives of Poly-carboxylate

\section{MODELLING WITH DECISION TREE}

The decision trees are usually used to classify the data set. The decision trees are similar to the supervising classification equation. The decision tree is a simple structure in which the internal nodes represent tests on one or more certain attributes and the end note are reflections of the decisions taken in the output. The common trees include root, branches, nodes, and leafs. The decision tree is usually drawn from left to right or from the root downward so it is easy to draw. It can make an important prediction and can describe the data set conceptually. There are various algorithms and to analyze them we can use the Weka box.

\subsection{J48}

Classification algorithms refer to the process of class model creation from the file sets including the class labels. The purpose of the decision tree algorithms is to find attributes-vector behaviours for some of the samples. Also according to the test samples, the classes of the newly produced sample are defined. This algorithm creates rules to predict the goal variable. With help of the decision tree algorithm, critical distribution of the data is understandable easily. J48 is an extension of ID3. The other features of $\mathrm{J} 48$ are calculation of the lost values, pruning the decision trees, continuous attributes value ranges, achieving the rule and so on. In WEKA data mining instrument, J48 is an open-source Java implementation of C4.5 algorithms. WEKA provides some options related to the decision tree pruning. Pruning can be used as a precision instrument in potential pre-process. In other algorithms, classification is done for every leaf recursively till all the leafs pruned, in other words to achieve a whole complete classification. This algorithm provides special rules to produce a specific identity from the data. The main goal is generalization of the decision tree until a balance of flexibility and accuracy is achieved.

\section{THE RESULTS}

Here we use WEKA instrument to implement the test. WEKA is an instrument box open-source machine leaning algorithms which is implemented by Java. WEKA is the abbreviation for Waikato Environment for Knowledge Analysis and has been developed in Waikato University, New Zealand. This instrument includes models like data processing, classification, clustering and extracting community rules. It includes a variety of data formats of which the more functional one is ARFF.

\subsection{Data set}

Concrete compressive strength data set taken from UCI machine learning repository (available in http://archive.ics.uci.edu/ml/) selected as the test data [9]. This data set includes 1030 samples each consists of 8 input variables: cement $(\mathrm{kg} / \mathrm{m} 3)$, fly ash $(\mathrm{kg} / \mathrm{m} 3)$, water $(\mathrm{kg} / \mathrm{m} 3)$, superplasticizer $(\mathrm{kg} / \mathrm{m} 3)$, coarse aggregate $(\mathrm{kg} / \mathrm{m} 3)$, fine aggregate $(\mathrm{kg} / \mathrm{m} 3)$ and age (day). The output variable is the concrete compressive strength (MPa). 
Civil Engineering and Urban Planning: An International Journal (CiVEJ ) Vol.4, No.1, March 2017

In this test 936 samples and 5 variables have been analyzed. All the samples are categorized into 5 classes which include:

1st class (A): $3 \mathrm{MPa}<$ samples $<10 \mathrm{MPa}$

2st class (B): $10 \mathrm{MPa}<$ samples $<30 \mathrm{MPa}$

3st class (C): $30 \mathrm{MPa}<$ samples $<40 \mathrm{MPa}$

4st class (D): $40 \mathrm{MPa}<$ samples $<50 \mathrm{MPa}$

5st class (E): $50 \mathrm{MPa}<$ samples $<60 \mathrm{MPa}$

\subsection{Evaluation with different algorithms of the decision tree}

At the end different results obtained of which the results of J48 were the best, so it is the best among the mentioned algorithms. Table 3 shows the accuracy percentage of the classification. As it is shown in figure 1, the J48 algorithm is the more accurate one. Figure 1 and 2 show its advantage in comparison to the others. The worst function belongs to the Decision Stump tree: Recall $=0.384$, F-measure $=0.256$, Precision $=0.200$, and the best belongs to J48: Recall $=0.745$, Fmeasure $=0$. 741, Precision $=0.764$. The results obtained verify the advantage of this algorithm over its counterparts. So J48 algorithm cab is selected as best.

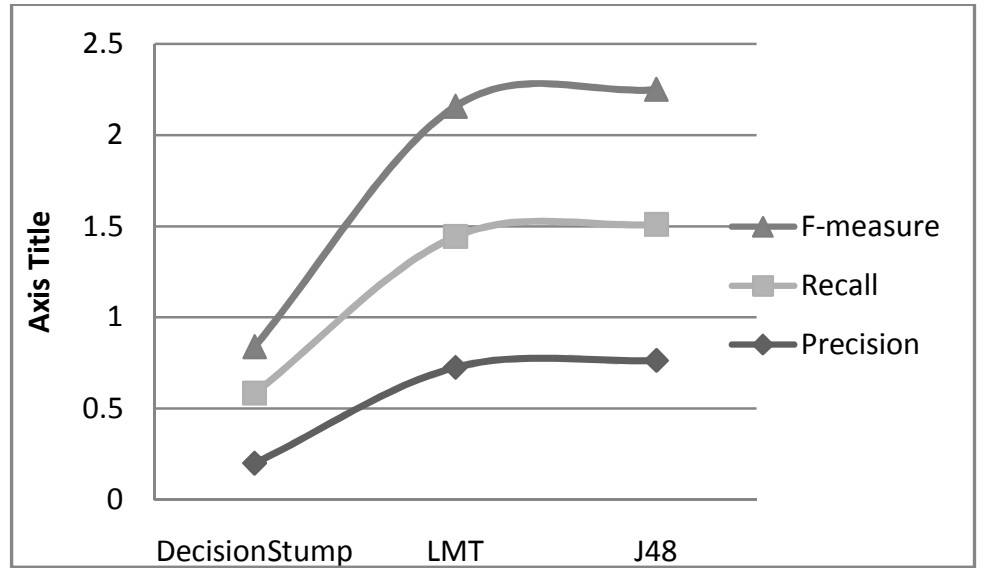

Figure 1: comparing the accuracy and precision of the decision tree algorithms using the linear diagram

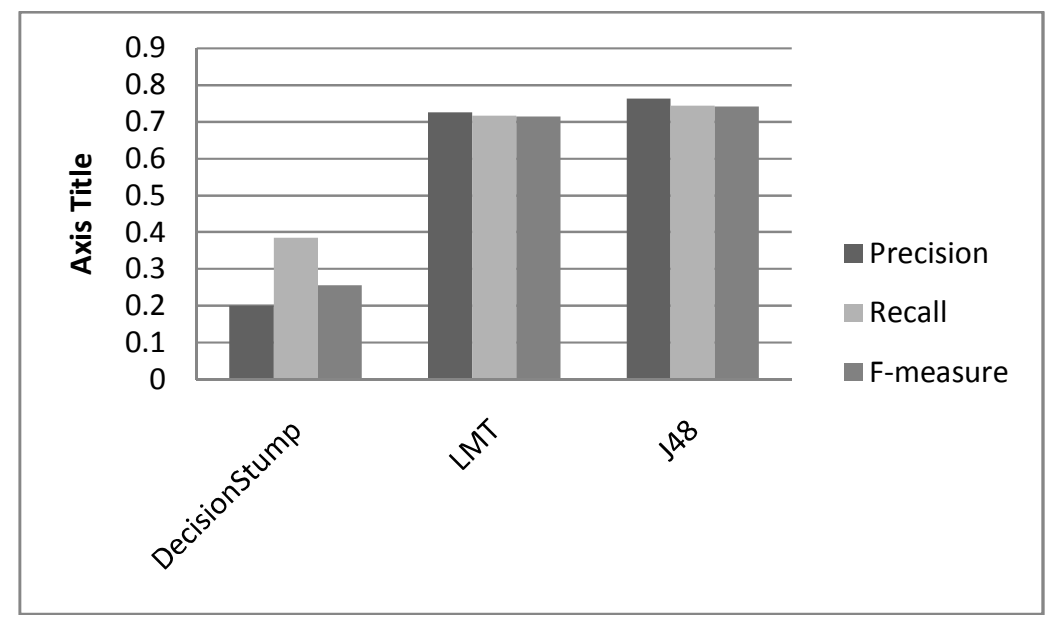

Figure 2: comparing the accuracy and precision of the decision tree algorithms using the bar diagram 


\subsection{Analysis of the test with $\mathrm{J} 48$ algorithm}

Usually the decision trees are used to classify a set of data. The decision trees are built in J48 algorithm using the information entropy on a set of data. J48 is a recursive algorithm that combines the remaining of the following data sets and continues normalizing the output data using the separation process until a uniform classification result obtained. Here the decision tree $\mathrm{J} 48$ is used for classification and the tree created after test implementation has been shown in figure 2. This tree consists of 120 leafs and 239 nodes.

\subsection{The findings obtained from the created tree}

To understand and apply the output rules, they are created in IF ... Then format and has been extended by the $\mathrm{J} 48$ algorithm. Table 1 shows some of the classification rules which has been produced by the $\mathrm{J} 48$ algorithm (focused on the analysis of the relation of the superplasticizers and the concrete compressive strength).

Table 1: Some of the classification rules which has been produced by the J48 algorithm [age=day, blast $\mathrm{f}=$ Blast Furnace Slag, sup $=$ Superplasticizer, Fly ash= Fly ash ]

\begin{tabular}{|c|c|c|}
\hline Rule name & Rule condition & $\begin{array}{l}\text { Predicted class } \\
\text { [Concrete } \\
\text { compressive } \\
\text { strength] }\end{array}$ \\
\hline Rule 1 & age $>28 \& \&$ blast $<=54.6 \& \&$ sup $<=3.9$ & Class D $=40(3.0)$ \\
\hline Rule 2 & blast_f $>102 \& \&$ age $>28 \& \&$ sup $<=3.9$ & Class $\mathrm{E}=50(3.0)$ \\
\hline Rule 3 & blast_f $<=76 \& \&$ age $>28 \& \&$ sup $<=3.9$ & Class $E=50(3.0 / 1.0)$ \\
\hline Rule 4 & age $>28 \& \&$ blast_f $<=54.6 \& \&$ sup $<=3.9$ & Class $\mathrm{D}=40(3.0)$ \\
\hline Rule 5 & sup $<=9.8 \& \&$ blast_f $<=26 \& \&$ age $<=28$ & Class $\mathrm{C}=30(2.0 / 1.0)$ \\
\hline Rule 6 & Fly_ash $<=137.9 \& \&$ age $<=28 \& \&$ sup $<=10.1$ & Class $\mathrm{A}=10(6.0)$ \\
\hline Rule 7 & Fly_ash $<=137.9 \& \&$ age $<=28 \& \&$ sup $<=11.3$ & Class $\mathrm{A}=10(6.0 / 2.0)$ \\
\hline Rule 8 & age $<=28 \& \&$ blast_f $<=184 \& \&$ Fly ash $<=59$ & Class $B=20(8.0 / 2.0)$ \\
\hline Rule 9 & $\begin{array}{c}\text { blast }<=47.5 \& \& \text { age }>28 \& \& \text { sup }<=8.8 \& \& \\
\text { fly_ash }<=95.7\end{array}$ & Class $\mathrm{E}=50(3.0 / 1.0)$ \\
\hline Rule 10 & Fly ash $>174.7 \& \&$ age $>7 \& \&$ blast_f $<=50.1$ & Class $\mathrm{A}=10(15.0)$ \\
\hline Rule 11 & age $<=7 \& \&$ sup $(4.1$ to 8.3$) \& \&$ fly ash $<=167$ & Class $\mathrm{A}=10(26.0)$ \\
\hline Rule 12 & age $<=7 \& \&$ sup $<=2.2 \& \&$ flash $<=167$ & Class $\mathrm{A}=10(50.5 / 5.0)$ \\
\hline Rule 13 & age $(3$ to 7$) \& \&$ sup $>15 \& \&$ blast_f $>111$ & Class $\mathrm{E}=50(3.0 / 1.0)$ \\
\hline Rule 14 & blast_f $>262.2 \& \&$ age $>28 \& \&$ sup $<=3.9$ & Class $\mathrm{E}=50(2.0)$ \\
\hline Rule 15 & $\begin{array}{c}\text { blast_f }>190 \& \& \text { age }>28 \& \& \text { sup }<=3.9 \& \& \& \\
\text { fly_ash }<=59\end{array}$ & Class $E=50(3.0 / 1.0)$ \\
\hline Rule 16 & blast_f $<=115 \& \&$ age $>28 \& \&$ sup $<=3.9$ & Class $\mathrm{E}=50(5.0)$ \\
\hline Rule 17 & age $<=2 \overline{8} \& \&$ sup $<=8.8 \& \&$ Fly_ash $<=147.7$ & Class $B=20(34.09 .0)$ \\
\hline Rule 18 & age $>28 \& \&$ blast_f $<=102 \& \&$ sup $<=3.9$ & Class $\mathrm{D}=40(3.0)$ \\
\hline Rule 19 & age $<=28 \& \&$ sup $<=8.1 \& \&$ Fly_ash $<=59$ & Class $B=20(34.09 .0)$ \\
\hline Rule 20 & blast_f $<=47.5 \& \&$ age $>28 \& \&$ sup $>13.9$ & Class $E=50(4.0)$ \\
\hline Rule 21 & fly ash $>158 \& \&$ age $<28$ blast_F & Class $\mathrm{C}=30(2.0 / 1.0)$ \\
\hline Rule 22 & $\begin{array}{c}\text { age }<=28 \& \& \text { sup }>12.2 \& \& \text { blast_f }<=143 \\
\& \& \text { fly_ash }>98\end{array}$ & Class $\mathrm{C}=30(7.0 / 1.0)$ \\
\hline
\end{tabular}


Civil Engineering and Urban Planning: An International Journal (CiVEJ ) Vol.4, No.1, March 2017

Some of the findings obtained from the rules of the established tree are as follows:

- If the amount of the superplasticizer in the mixture is lower than the cement, then the concrete compressive strength decreases like the rules (Rule 11 and Rule 12) available in table 1 which both are equal to Class $\mathrm{A}=10 \mathrm{MPa}$.

- In this test according to the built tree and the created rules, if age $>28$ and $3.8<\sup <8.8$ then class D is more predictable like the Rules 2, 3, 14 and 15.

- According to this data set, it is concluded that if the amount of the superplasticizer is higher in the mixture of the concrete then concrete compressive strength increases. For example, if age $>28 \&$ blast $f>47.5 \&$ sup $>13.9$ then concrete compressive strength will be Class A = $50 \mathrm{MPa}$.

\section{CONCLUSION}

According to the implemented tests, we conclude that the concrete mixture 3 days $<$ age $<28$ days will not gain the required compressive strength even with presence of the superplasticizer; So to have a concrete with a high compressive strength needs time. The superplasticizers have a key role in the concrete compressive strength increase.

\section{REFERENCES}

1. Malhotra VM. Innovative applications of superplasticizers in concrete-A review. In: Mehta PK, editor. Proceedings of Mario Collepardi Symposium on Advances in Concrete Science and Technology 5th CANMET/ACI International Conference on Superplasticizers and Other Chemical Admixtures Rome, 7-10 October 1997. p. 271-314.

2. Langley WS, Carette GG, Malhotra VM. Structure concrete incorporating high volume of ASTM class F fly ash. ACI Mater J . 1989;86:507-14.

3. Rixom, R., and Mailvaganam, N., 2000. Chemical Admixtures for concrete. E \& F Spon books, 464.

4. Sidney, M. Levy. 2011. Construction Calculations Manual. Elsevier, Technology and Engineering Books, 225.

5. Jerath, S., and Yamane, L.C. 1987. Mechanical properties and workability of super-plasticized concrete. Cement, Concrete and Aggregates, 9(1), 12-19.

6. Tattersall, G., H., and Bloomer, S., J. 1979. Further development of the two point test for workability and extension of its range. Magazine of concrete research, 31(2), 202-210.

7. Shah, S. N. R., Aslam, M., Shah, S. A., \& Oad, R. (2016). Behaviour of Normal Concrete using Superplasticizer under Different Curing Regimes. Pakistan Journal of Engineering and Applied Sciences.

8. Erdogdu, S. 2005. Effect of re-tempering with superplasticizer admixtures on slump loss and compressive strength of concrete subjected to prolonged mixing. Cement and Concrete Research, 35(5), 907-912.

9. archive.ics.uci.edu/ml/machine-learning-databases/concrete/compressive/

10. Coutinho A., Production and properties of concrete (in Portuguese), LNEC, Lisbon, Portugal, 1988, $401 \mathrm{p}$.

11. Pereira P., Evangelista L., de Brito J., The effect of superplasticizers on the workability and compressive strength of concrete made with fine recycled concrete aggregates, Construction and Building Materials 2011, 28 (1): 722-729. 
Civil Engineering and Urban Planning: An International Journal (CiVEJ ) Vol.4, No.1, March 2017

12. Pereira P, Evangelista L, de Brito J. The effect of superplasticizers on the mechanical performance of concrete made with fine recycled concrete aggregates. Cement and Concrete Composites 2012; 9 (34): 1044-1052.

13. Yamakawa I., Kishtiani K., Fukushi I., Kuroha K., Slump Control and Properties of Concrete with a New Superplasticizer. II. High strength in situ concrete work at Hicariga-Oka Housing project, RILEM Symposium on "Admixtures for Concrete. Improvement of Properties", Editor: E. Vasquez, Chapman \& Hall, London, pp 94-105 (1990). 